\title{
Palabras del Licenciado Gustavo Benedicto en la puesta en circulación de su libro "Redacción de Documentos."
}

Perdido en la lejanía de una época pasada, se ubica aquel momento en que un joven adolescente, imberbe aún, llegó a orillas del río Tagüey, afluente del Yaguajal en la legendaria Sabaneta, hoy Șantiago Rodríguez, con la misión de alfabetizar los niños de esos agrestes predios.

Este fue sin duda, el primer paso para que se despertaran aptitudes latentes en aquel joven, quien desde allí en adelante adoptó la carrera magisterial; recorrió con esta misión numerosas poblaciones del país e impartió clases en todos los grados de la enseñanza primaria e intermedia, comprendió también la mayor parte de las disciplinas de la secundaria y específicamente la docencia de la lengua castellana en sus diversos aspectos, enseñándola posteriormente en academias comerciales y centros de educación superior de la ciudad de Santo Domingo.

La Universidad Nacional Pedro Henríquez Ureña, madre generosa que ha prohijado tantas aspiraciones y anhelos legítimos de superación, acogió a aquel enamorado de la enseñanza, ya transcurrido el tiempo, y.le ofreció, primero sus ópimas lecciones y después le permitió, ya bien provisto de más sólidos y nuevos conocimientos, el privilegio de continuar su trayectoria de maestro, al servicio de una juventud que hurga en lo arcano, para ser más útil y más buena.

Estas aseveraciones, quieren 
cxplicar por qué, quien tiene el honor de dirigirles la palabra' les ofrece un libro que trata de inducir a un mejor empleo del idioma castellano, demostrando cómo las raíces del presente están aterradas en el prisado, pues aquel adolescente, simple maestro de campo, peregrino desde el Yaguajal, es a quien ustedes escuchan ahora

En realidad, nuestro mayor empeño es dejar plasmada en el pensamiento de nuestros congéneres la idea de que en este mundo de fases tan cambiantes, cada quien está obligado a ofrecer aportes, no sólo materiales, que son los de menos valor, sino intelectuales y sobre todo espirituales.

Deseamos acentuar además, el hecho de que el libro "Redacción de Documentos" se pone a circular en Santiago, nuestra venerable cuna, origen de nuestros antepasados, que como Amado Benedicto, padre ejemplar, y Enilio Benedicto y Clara Deschamps, abuelos generosos, nos ofrecieron el cariño, la protecsiór y buenas costumbres para que camináramos por la senca de la vida con pasos rectos y firmes. También Santiago nutrió nuestro intelecto desde el aprendizaje de las primeras letras en la escuela primaria, conducidos por Milita Colón y Caridad Cordero y ya en nuestra adolescencia Emma Balaguer, Virgilio de Peña y Onésimo Jiménez, entre muchos, nos abrieron las puertas del saber bello y profundo de la grramática y la literatura castellana.

Pero para nosotros cobra aún mayor significado, la circunstancia de que el Ateneo Amantes de la Luz, surgido al calor de los ideales sustentados por nuestros tíos Manuel de Jesús Peña y Reinoso, Eugenio Deschamps y Enrique Deschamps, es precisamente el lugar en donde celebramos este evento, pues aquí en su biblioteca tuvimos la oportunidád no sólo de estudiar los libros de texto que señalaban nuestros maestros, sino que también viajamos en alas de la imaginación y la fantasía a través del Tesoro de la Juventud; Julio Verne, Emilio Salgari, José Eustasio Rivera, Gustavo Flaubert, Jorge Isaac, Victor Hugo, Alejandro Dumas padre e hijo y de un sinnúmero de gigantes de las ideas, que poblaban sus anaqueles fecundos, atendidos solícitamente por un humilde y servicial bibliotecario llamado Masú, cuyo recuerdo permanece en la memoria de muchas generaciones de lectores agradecidos que han tenido esta biblioteca como su segundo hogar.

Es indudable que el Universo se mantiene gracias a las condiciones de equilibrio que prevalecen en todos. los órdenes dentro de él. Nuestra propia existencia es una demostración de la maravillosa armonía que impera en ese Universo complejo, pletórico de miríadas de estrellas, galaxias y planetas que se mueven a velocidades increíbles por el espacio inconmesurable, pero sincronizados en su acción por leyes eternas. Si estamos dotados de vida ahora, esto se debe al perfecto orden que se manifiesta en los más pequeños 
detalles que propicia la Naturaleza en lo físico, en lo químico, en lo biológico, lo intelectual y lo espiritual; repartidos de manera tan severamente crítica que nos parece un milagro su permanencia por los siglos de los siglos.

Nosotros, como parte principal de la Naturaleza, somos agentes conscientes o inconscientes de ella para mantener ese equilibrio, procurando con nuestràs acciones balancear adecuadamente el debe y el haber de la vida; retornando a los que nos proveyeron alimentos, aire, luz, calor, ideas y conocimientos, esos mismos valores. Nuestra presencia aquí, hoy, no es más que el cumplimiento de un irrefrenable deseo de devolver a nuestro lar nativo, algo de lo mucho que hemos recibido de él, para así dejar satisfecha, en parte, la inmutable ley de la retribución.

La palabra, escrita o hablada, es la encarnación más genuina del Gran Arquitecto del Universo, es la cualidad que permite al hombre diferenciarse de las demás cosas creadas, pues a su influjo se transforma la faz de la tierra y siendo poseedor de esta formidable herramienta, penetra las reconditeces del intelecto y del espíritu haciendo luz en las conciencias y creando belleza para solaz de las almas sensitivas. Si poseemos el don de la palabra ipor qué no afanarnos en perfeccionar su expresión? ¿No es más eficaz el mensaje que llevan éstas cuando están correctas y bellamente expresadas? ¿No es acaso signo de aristocracia del espíritu alcanzar la perfección que exhibieron en este campo Cervantes, Lope de Vega, Unamuno, García Lorca, Castelar y Pedro Henríquez Ureña? ¿No debería, por último, ser para nosotros aspiración suprema emular esas cumbres con el desarrollo del pensamiento y las letras?

$L$ as respuestas afirmativas a todas esas inquietudes deberían conducirnos a ser cultores del buen decir, con el estudio profundo de las obras de los iluminados y la práctica consuetudinaria de la elegancia en el pensar, hablar o escribir, pues de esa manera lograríamos acercarnos un poco más a quien es origen y fin de toda la creación.

Repetía un amigo ya desaparecido, que lo más difícil es encontrar un hombre en un acto que le sea auténticamente propio, $y$ esto es evidente, pues somos un amasijo de todo el andamiaje genético conformado por nuestros cromosomas, trayendo desde lo más recóndito de eras perdidas en la historia, los hábitos, gustos, habilidades y talentos que al pasar a los niveles de conciencia actuales se unen a las experiencias y conocimientos de los demás seres humanos por medio del estudio y la socialización. En el caso de la obra que hoy se pone a circular, lo aportado por el autor, es en gran medida, su buena voluntad; el acervo de muchos connotados intelectuales se manifiesta en sus renglones y la ayuda desinteresada de valiosos colaboradores como el 
Dr. Raymundo Amaro Guzmán, a través de ONAP, Dr. Mariano Lebrón Saviñón, revisor de la obra y coautor del tema que se refiere a la composición y derivación de las palabras; Narciso Peñaló, José Miguel Jiménez, Elizabeth Hart, Yolanda Nova, Porfirio Quezada, Juan Forzani, Viviana Alcántara, Teófilo Rodríguez, Ramón Velazco, Narciso Silveiro y numerosas personas más, da lugar a que este libro tenga la característica esencial de ser producto de muchos; en eso reside el mérito que pueda tener. También la notable política editorial emprendida por ONAP, es responsable de esta publicación, pues ha permitido que estos volúmenes estén a disposición de aquéllos que se interesan por ser mejores cada día a través de su cultura y desarrollo intelectual.

Para concluir, debemos reiterar el sentimiento de gran estima a todas las personas que se han solidarizado con este acto asistiendo a él, lo cual hace que renovemos la $\mathrm{fe}$ en nuestros conciudadanos, pues son el testimonio de que aún nos interesamos en congregarnos con propósitos constructivos y altruistas.

Muchas Gracias. 